\title{
In vitro equivalence of generic and branded amoxicillin tablet by microbiological assay method by Isnaeni Isnaeni
}

Submission date: 11-Jun-2020 11:57AM (UTC+0800)

Submission ID: 1341693103

File name: d_branded_amoxicillin_tablet_by_microbiological_assay_method.pdf (92.31K)

Word count: 3124

Character count: 15432 
Primadi Avianto' $/$ Mahfudz $^{1,2} /$ Suharjono $^{3}$ / Isnaeni ${ }^{4}$ / Christopher Paul Alderman ${ }^{3,5}$

\section{In vitro equivalence of generic and branded amoxicillin tablet by microbiological assay method}

1 Faculty of Pharmacy, Universitas Airlangga, Master Program in Clinical Pharmacy, Department of Clinical Pharmacy, Kampus C, UNAIR, Mulyorejo Rd. Surabaya, Indonesia, E-mail: primadi-a-11@ff.unair.acid

${ }^{2}$ Pharmacy Section, Bangka Tengah District Health Office, Bangka Belitung, Indonesia

${ }^{3}$ Faculty of Pharmacy, Universitas Airlangga, Department of Clinical Pharmacy, Kampus C, UNAIR, Mulyorejo Rd. Surabaya, Indonesia

${ }^{4}$ Faculty of Pharmacy, Universitas Airlangga, Department of Pharmaceutical Chemistry, Kampus C, UNAIR, Mulyorejo Rd. Surabaya, Indonesia

${ }^{5}$ School of Pharmacy and Medical Sciences, University of South Australia, Adelaide, Australia

\section{Abstract:}

Background: Indonesian Ministry of Health advocate doctors, especially in government-owned healthcare facility, to prescribe generic drugs including amoxicillin. Although BPOM (the National Agency of Drug and Food Control) already guarantees that the generic amoxicillin and the branded one were interchangeable, lack of confidence in generic drugs still remains among patients, pharmacists, and doctors. This 1 is supported by lack of publication confirmed the therapeutic equivalence of branded and generic drugs. This study aims to evaluate and compare the in vitro microbiological assay of different generic and branded amoxicillin that are available in Indonesian market, es 1 ecially those used in government-owned healthcare facilities.

Methods: Microbiological assays for five samples of amoxicillin tablet containing $500 \mathrm{mg}$ amoxicillin available in Indonesia were determined using a method from Indonesia Pharmacopeia. Samples were coded as Products A to E. The assay was carried out by measuring the diameter of the inhibition zones in the plate agar incubated with Escherichia coli and Staphylococcus aureus. The obtained data were evaluated to determine the sample potency and compared with the amoxicillin refirence standard.

Results: Minor and insignificant differences $(\mathrm{p}>0.05)$ were found in the diameters of the inhibition zones. Potency ratio measured both in E. coli and S. aureus were all between $95 \%$ and $105 \%$. The lowest of the tested samples were from Product C, which resulted to ratio potencies of $96.3 \%$ and $95.5 \%$ in E. coli and S. aureus, respectively.

Conclusions: All five samples were in the range of the acceptance criteria. Therefore, from the view of the microbiological assay, these products are in equivalence in quality and are interchangeable.

Keywords: amoxicillin, generic substitution, microbiological assay

DOI: $10.1515 /$ jbcpp-2019-0247

Received: September 4, 2019; Accepted: November 22, 2019

\section{Introduction}

As the Indonesia Ministry of Health advocates doctors to prescribe generic medicine especially in governmentowned healthcare facilities such as primary health care centers (PHCCs) and hospitals, pros and cons debate reemerge [1]. For the pros, generic medicines could benefit patients because of its affordability without affecting treatment outcome (same efficacy). The cons argue that generic medicines are not always clinically equivalent and therefore do more harm than good despite ${ }_{6}$ its low cost [2], [3], [4]. Those that are clinically in-equivalent should be re 3 orted because the medicines were substandard (also called out of specification), which, according to $\mathrm{WHO}$, is defined as authorized medical products that fail to meet either their quality standards or specifications, or both [5]. Substandard medicine may have lower quality, therefore resulting in lower efficacy and different safety profile [6]. For substandard antibiotics, it may result in increased mortality, morbidity, and cost because of unmet clinical outcomes (unresolved infection), even the development of resistance bacteria. 
Beta-lactams were among the most commo 5 substandard medicines found. Predominantly, it was amoxicillin, a semisynthetic amino penicillin with bactericidal activity against many Gram-positive and Gramnegative bacteria [7]. This broad spectrum combined with its low cost and well-known safety profile results to its common use in various infections such as in the respiratory tract, ear, skin, and urinary tract.

Antibiotic use profile in Indonesia does not differ from the rest of the world. Beta-lactams was among the most used antibiotic, especially amoxicillin [8], [9], [10]. As one of the district in Indonesia, Bangka Tengah is predicted to have the same antibiotic use profile as the rest of Indonesia.

The present study aims to compare the efficacy of the generic and branded amoxicillin preparations used in PHCC and hospitals across Bangka Tengah district by comparing its antibacterial potency.

\section{Materials and methods}

In this study conducted in 2018, three generics and two brand preparations of amoxicillin from various manufacturers were collected from PHCC and a government-owned hospital in Bangka Tengah district. Those five products were all products that were available, circulating, and to be used for the patients in PHCC and the government-owned hospital in Bangka Tengah at the time of the sample collection. Those products then were labeled as products A through E. All samples were kept in manufacturer's original packing and stored as stated in its packaging until testing, that is, in dry and controlled room temperature $\left(<30^{\circ} \mathrm{C}\right)$. The amoxicillin reference $s_{2}$ andard (equivalent to Indonesian Pharmacopeia Reference Standard) was used for comparison, labeled as F. Escherichia 2 li (ATCC 25922) and Staphylococcus aureus (ATCC 25923) were used as the test bacteria in this study. Both E. coli and S. aureus were obtained from the Clinical Microbiology Department of Dr. Soetomo General Teaching Hospital in Surabaya, Indonesia. Sodium chloride 0.9\% (Widatra Pharmaceutical Industry, Pandaan, Indonesia) was used for the preparation of the test bacteria. A spectrophotometer (GENESYS ${ }^{\mathrm{TM}} 20$, Thermo Scientific) was used to measure the optical density of the test bacteria suspension to obtain $25 \% \mathrm{~T}$ (transmittance).

Microbiological assay to evaluate the in vitro potency comparison was carried out using agar diffusion method by $3 \times 3$ assay design. Mueller-Hinton agar (Oxoid, USA) was used as the growth media. MuellerHinton agar was weighed approximately $3 \mathrm{~g}$, then $150 \mathrm{~mL}$ of distilled water (Ikapharmindo Pharmaceutical Industry, Jakarta, Indonesia) was added. The mixture was heated while stirring evenly. Afterward, it was sterilized with an autoclave at $120{ }^{\circ} \mathrm{C}$ for $15 \mathrm{~min}$. The agar solution was then poured in Petri dishes at $40-50{ }^{\circ} \mathrm{C}$ and then left solid to be used as a base layer. The seed layer media was prepared by inoculating $5 \mu \mathrm{L} 25 \% \mathrm{~T}$ test microbial suspension containing $10^{9} \mathrm{CFU}$ of test microbe, poured over the surface of the compacted media layer.

Five tablets of amoxicillin from each sample were randomly selected, weighed, and homogenized. Approximately equivalent to $50 \mathrm{mg}$ amoxicillin was then put in a $10 \mathrm{~mL}$ measuring flask, added with $5 \mathrm{~mL}$ of DMSO (Merck, Germany) and sonicated. DMSO was added until $10 \mathrm{~mL}$ and then filtered with a membrane filter $(0.2$ $\mu \mathrm{m}$ ). Sonification was carried out to ensure all active ingredients were extracted from the tablet matrix (excipients). Furthermore, serial dilution was made to achieve 200,160, 128, 25, 20, and 16 ppm solutions. The standard solution was made by the same procedure.

Each Petri disk contains wells of each of the product, reference standard, and negative control (only containing diluent). For each product and reference, there were three wells, representing high (H), medium (M), and low (L) test concentrations. For the E. coli colony, concentrations used were as follows: $200(\mathrm{H}), 160(\mathrm{M})$, and $128 \mathrm{ppm}(\mathrm{L})$. For $S$. aureus, it was 25,20 , and $16 \mathrm{ppm}$. The zone of inhibition was measured by its diameter usi 4 caliper scale in millimeters after $22 \mathrm{~h}$ of incubation (Memmert Incubator, Germany).

Statistical analysis was done using one-way ANOVA followed by Tukey's test using the SPSS sof tware (version 22.0, IBM).

\section{Results}

The Agar diffusion test using E. coli showed that all products were comparable as shown in Table 1. Consistent results were seen in the tests using S. aureus as shown in Table 2. Further potency comparisons (Table 3 ) showed that for E. coli, product $C$ had the lowest potency of $96.3 \pm 1.7 \%$, and the highest was $98.2 \pm 1.3 \%$ from product B. For S. aureus, product A showed the lowest potency of $96.1 \pm 1.1 \%$, and product $C$ showed the highest potency of $97.7 \pm 0.2 \%$ 
Table 1: Diameter of inhibition zones of amoxicillin against E. coli (mm).

\begin{tabular}{|c|c|c|c|c|c|c|c|}
\hline \multirow[t]{2}{*}{ Replication } & \multirow[t]{2}{*}{ Conc. } & \multicolumn{6}{|c|}{ Product code } \\
\hline & & $\mathbf{A}$ & B & $\mathrm{C}$ & D & E & F (STD) \\
\hline \multirow{3}{*}{1} & High & $16.2 \pm 1.1$ & $16.6 \pm 0.4$ & $16.4 \pm 1.1$ & $16.5 \pm 0.7$ & $16.4 \pm 1.0$ & $16.6 \pm 1.1$ \\
\hline & Medium & $15.2 \pm 1.0$ & $15.6 \pm 0.6$ & $15.3 \pm 0.9$ & $15.3 \pm 0.7$ & $15.3 \pm 0.9$ & $15.6 \pm 1.0$ \\
\hline & Low & $14.2 \pm 0.9$ & $14.6 \pm 0.6$ & $14.3 \pm 0.7$ & $14.2 \pm 0.7$ & $14.3 \pm 0.8$ & $14.7 \pm 1.1$ \\
\hline \multirow{3}{*}{2} & High & $16.0 \pm 1.0$ & $16.0 \pm 0.4$ & $15.9 \pm 1.3$ & $16.1 \pm 0.6$ & $15.9 \pm 1.6$ & $16.6 \pm 1.0$ \\
\hline & Medium & $14.8 \pm 0.9$ & $15.3 \pm 0.7$ & $14.9 \pm 1.3$ & $14.9 \pm 1.1$ & $15.1 \pm 1.0$ & $15.7 \pm 1.1$ \\
\hline & Low & $13.9 \pm 1.0$ & $14.1 \pm 0.7$ & $13.5 \pm 0.7$ & $13.8 \pm 0.9$ & $13.9 \pm 1.0$ & $14.6 \pm 1.1$ \\
\hline \multirow{3}{*}{3} & High & $15.6 \pm 1.1$ & $16.1 \pm 0.3$ & $15.6 \pm 1.0$ & $16.3 \pm 1.1$ & $16.4 \pm 1.1$ & $16.6 \pm 1.0$ \\
\hline & Medium & $14.8 \pm 1.2$ & $15.1 \pm 0.5$ & $14.7 \pm 0.7$ & $15.1 \pm 0.5$ & $14.6 \pm 1.0$ & $15.6 \pm 1.2$ \\
\hline & Low & $14.3 \pm 0.8$ & $14.4 \pm 0.9$ & $14.1 \pm 0.6$ & $13.9 \pm 0.9$ & $13.9 \pm 0.7$ & $14.6 \pm 1.1$ \\
\hline Sum & & $45.0 \pm 2.6$ & $45.9 \pm 1.5$ & $44.9 \pm 2.7$ & $45.3 \pm 2.2$ & $45.3 \pm 2.8$ & $46.9 \pm 3.0$ \\
\hline p-Value & & $>0.05$ & $>0.05$ & $>0.05$ & $>0.05$ & $>0.05$ & $\mathrm{na}^{\mathrm{a}}$ \\
\hline
\end{tabular}

a not applicable, $\mathrm{F}$ was used as reference standard against product $\mathrm{A}$ to $\mathrm{E}$.

Table 2: Diameter of inhibition zones of amoxicillin against S. aureus (mm).

\begin{tabular}{|c|c|c|c|c|c|c|c|}
\hline \multirow[t]{2}{*}{ Replication } & \multirow[t]{2}{*}{ Conc. } & \multicolumn{6}{|c|}{ Product code } \\
\hline & & A & B & $\mathrm{C}$ & D & E & F (STD) \\
\hline \multirow{3}{*}{1} & High & $16.1 \pm 0.5$ & $16.2 \pm 0.6$ & $15.7 \pm 0.6$ & $16.1 \pm 0.3$ & $16.0 \pm 0.6$ & $16.6 \pm 0.2$ \\
\hline & Medium & $14.6 \pm 0.4$ & $14.6 \pm 0.5$ & $14.5 \pm 0.4$ & $14.7 \pm 0.3$ & $14.5 \pm 0.5$ & $15.1 \pm 0.2$ \\
\hline & Low & $13.4 \pm 0.4$ & $13.5 \pm 0.3$ & $13.5 \pm 0.5$ & $13.5 \pm 0.4$ & $13.3 \pm 0.6$ & $13.5 \pm 0.3$ \\
\hline \multirow{3}{*}{2} & High & $15.9 \pm 0.7$ & $16.2 \pm 0.5$ & $16.0 \pm 0.8$ & $16.0 \pm 0.9$ & $16.1 \pm 0.8$ & $16.7 \pm 0.4$ \\
\hline & Medium & $14.3 \pm 0.2$ & $14.4 \pm 0.6$ & $14.6 \pm 0.6$ & $14.6 \pm 0.4$ & $14.8 \pm 0.7$ & $15.0 \pm 0.3$ \\
\hline & Low & $12.8 \pm 0.5$ & $13.3 \pm 0.8$ & $13.2 \pm 0.6$ & $13.4 \pm 0.5$ & $13.2 \pm 0.8$ & $13.3 \pm 0.4$ \\
\hline \multirow{3}{*}{3} & High & $15.6 \pm 1.1$ & $16.1 \pm 0.3$ & $15.6 \pm 1.0$ & $16.3 \pm 1.1$ & $16.4 \pm 1.1$ & $16.6 \pm 1.0$ \\
\hline & Medium & $14.8 \pm 1.2$ & $15.1 \pm 0.5$ & $14.7 \pm 0.7$ & $15.1 \pm 0.5$ & $14.6 \pm 1.0$ & $15.6 \pm 1.1$ \\
\hline & Low & $14.3 \pm 0.8$ & $14.4 \pm 0.9$ & $14.1 \pm 0.6$ & $13.9 \pm 0.9$ & $13.9 \pm 0.7$ & $14.3 \pm 0.9$ \\
\hline Sums & & $43.9 \pm 1.9$ & $44.6 \pm 1.4$ & $43.9 \pm 1.6$ & $44.4 \pm 1.6$ & $44.3 \pm 2.0$ & $45.6 \pm 1.7$ \\
\hline p-Value & & $>0.05$ & $>0.05$ & $>0.05$ & $>0.05$ & $>0.05$ & $\mathrm{na}^{\mathrm{a}}$ \\
\hline
\end{tabular}

a not applicable, F was used as reference standard against product A to E.Add a table footnote here

Table 3: Potency of tested product compared with the standard.

\begin{tabular}{lrrrrr}
\hline Colony & \multicolumn{3}{c}{} & \multicolumn{2}{c}{ Product code } \\
\cline { 2 - 6 } & A & B & C & D & E \\
\hline E. coli & $96.5 \pm 0.9 \%$ & $97.2 \pm 1.3 \%$ & $96.3 \pm 1.7 \%$ & $97.1 \pm 0.9 \%$ & $97.0 \pm 1.2 \%$ \\
S. aureus & $96.1 \pm 1.1 \%$ & $97.7 \pm 0.2 \%$ & $96.2 \pm 0.5 \%$ & $97.4 \pm 0.2 \%$ & $97.0 \pm 0.5 \%$ \\
\hline
\end{tabular}

Indonesian Pharmacopoeia requirements: $95-102 \%$

\section{Discussion}

The National Agency of Drug and Food Control (BPOM) has made thorough regulations for medicine manufacturers, often called cGMP (current good manufacturing practices) [11]. This cGMP is applied both for generic and branded medicines. It is requiring the manufacturers to extensively test the products both in vitro and in vivo before being made available to the public. Even in post marketing situation, BPOM are rigorously testing medicines that are already in the market with random sampling from pharmacies, PHCC, and hospitals from across the country [12], [13]. Therefore, there should be no reason to believe that generic medicines are substandard. 
Availability of generic drugs, which are generally lower in cost compared with their branded counterparts, is important especially for developing country such as Indonesia. With low cost and same quality, not only high income people could afford the medicines they needed but also people with middle and low income.

The present study used agar diffusion method, which is also known as cylindrical-plate method. This method is one of the most widely used method to estimate potency/bioactivity of antibiotics [14]. It is very important to have equivalent quality, efficacy, and safety in the various preparations of amoxicillin, as it is the most used antibiotic in the healthcare system in Indonesia. The results shown above revealed that all brands, both generic or branded, that were used for the patients in PHCC and government-owned hospital in Bangka Tengah were comparable in potency. All products were also in the range of acceptance, which is $95 \%-102 \%$ according to the Indonesia Pharmacopoeia.

Various other studies conducted elsewhere show mixed results; some studies show comparable in vitro quality between generic and branded medicines, whereas others show that generic medicines were not comparable with the branded ones, especially the innovator brand [15], [16], [17], [18]. Substandard medicine may lead to treatment failure, such as that shown for antimalarial and antitubercular agents. This predominantly occurs in less developed countries in Africa and Asia, in some extent in Europe [7], [19]. Treatment failure means increase in cost, mortality, and morbidity. This suggests that intensive and rigorous manufacturing guidelines and product quality surveillance, as is already done by BPOM, must be kept in pace to prevent substandard medicine from corrupting the quality of health care in Indonesia.

Research funding: None declared.

Author contributions: All authors have accepted responsibility for the entire content of this manuscript and approved its submission.

Competing interests: Authors state no conflict of interest.

\section{References}

[1] Indonesia Ministry of Health. Kewajiban menggunakan obat generik di fasilitas kesehatan pemerintah, 2010. Available from: http://jdih.pom.go.id/showpdf.php?u=475 (Accessed 2 June 2019).

[2] Dunne SS, Dunne CP. What do people really think of generic medicines? A systematic review and critical appraisal of literature on stakeholder perceptions of generic drugs. BMC Med 2015;13:173.

[3] Colgan S, Faasse K, Martin LR, Stephens MH, Grey A, Petrie K]. Perceptions of generic medication in the general population, doctors and pharmacists: a systematic review. BM] Open 2015;5:e008915

[4] Hermansyah A, Athiyah U, Setiawan CD. Are patients willing to ask for generic drug substitutions? I]PTP 2013;4:832-7.

[5] SFMedical Products Group, Essential Medicines and Health Products WHO. WHOMember State Mechanism on Substandard/Spurious/Falsely-Labelled/Falsified/Counterfeit (SSFFC) Medical Products. Seventieth World Health Assembly [Internet]. 2017:33-6. Available at: http://www.who.int/medicines/regulation/ssffc/A70_23-en1.pdf ?ua=1. (Accessed 2 August 2019)

[6] Johnston A, Holt DW. Substandard drugs: a potential crisis for public health. Br] Clin Pharmacol 2014:78:218-43.

[7] Kelesidis T, Falagas ME. Substandard/counterfeit antimicrobial drugs. Clin Microbiol Rev 2015;28:443-64.

[8] Andrajati R, Tilaqza A, Supardi S. Factors related to rational antibiotic prescriptions in community health centers in Depok City, Indonesia. J Infect Public Health 2017;10:41-8.

[9] Pradipta I, Kartikawati A, Hartanto H, Febrina E, Ronasih E, Abdulah R, et al. Three years of antibacterial consumption in Indonesian community health centers: the application of anatomical therapeutic chemical/defined daily doses and drug utilization $90 \%$ method to monitor antibacterial use.] Fam Community Med 2015;22:101.

[10] WHO. WHO report on surveillance of antibiotic consumptions. 2018. Available from: https://www.who.int/medicines/areas/rational_use/oms-amr-amc-report-2016-2018/en/(Accessed 18 May 2019).

[11] BPOM. Cara Pembuatan Obat yang Baik dan Benar. Badan Pengawas Obat dan Makanan 2018;53:1689-99.

[12] BPOM. Laporan Kinerja BPOM 2017. 2017. Available from: www.pom.go.id/new/admin/dat/20180710/Laporan\%20Kinerja\%20BPOM\%20 Tahun\%202017.pdf (Accessed 18 May 2019).

[13] Indonesia Ministry of Health. Penyelenggaraan Uji Mutu Obat pada Instalasi Farmasi Pemerintah. Available from: jdih.pom.go.id/showpdf.php?u=rs8l1\%2BA7zYojhTEWr6SIz808hnGJGvmDDq6w5EJbNKE\%3D (Accessed 2 June 2018).

[14] Dafale NA, Semwal UP, Rajput RK, Singh CN. Selection of appropriate analytical tools to determine the potency and bioactivity of antibiotics and antibiotic resistance. J Pharm Anal 2016;6:207-13.

[15] Pathak P, Dawane ]. In vitro comparison of generic and branded preparations of amoxicillin with potassium clavulanate. ] Clin Diagnostic Res 2016;10:FC07-9.

[16] Diaz ]A, Silva E, Arias M], Garzón M. Comparative in vitro study of the antimicrobial activities of different commercial antibiotic products of vancomycin. BMC Clin Pharmacol 2011;11:9.

[17] Silva E, Díaz ]A, Arias M], Hernández AP, de la Torre A. Comparative in vitro study of the antimicrobial activities of different commercial antibiotic products for intravenous administration. BMC Clin Pharmacol 2010;10:3 
[18] Kassaye L, Genete G. Evaluation and comparison of in-vitro dissolution profiles for different brands of amoxicillin capsules. Afr Health Sci 2013:13:369-75.

[19] Delepierre A, Cayot A, Carpentier A. Update on counterfeit antibiotics worldwide; public health risks. Med Mal Infect 2012;42:247-55. 
In vitro equivalence of generic and branded amoxicillin tablet by microbiological assay method

ORIGINALITY REPORT

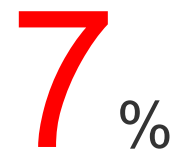

SIMILARITY INDEX
$6 \%$

INTERNET SOURCES
$3 \%$

PUBLICATIONS
$0 \%$

STUDENT PAPERS

\section{PRIMARY SOURCES}

1 repository.unair.ac.id

2 Ying Ma, Pengtao Liu, Chuanling Si, Zhong Liu.

"Chitosan Nanoparticles: Preparation and

Application in Antibacterial Paper", Journal of

Macromolecular Science, Part B, 2010

Publication

3 jamanetwork.com

Internet Source

4 www.mdpi.com

Internet Source

$5 \quad$ www.jourlib.org

Internet Source

6 Serena Vickers, Matthew Bernier, Stephen

Zambrzycki, Facundo M Fernandez, Paul N

Newton, Céline Caillet. "Field detection devices

for screening the quality of medicines: a

systematic review", BMJ Global Health, 2018 
Exclude quotes

Off

Exclude matches

Off

Exclude bibliography

On 


\section{In vitro equivalence of generic and branded amoxicillin tablet by microbiological assay method}

GRADEMARK REPORT

FINAL GRADE

10

PAGE 1

PAGE 2

PAGE 3

PAGE 4

PAGE 5
GENERAL COMMENTS

Instructor 